\title{
Effects of Thymus daenensis on inflammatory factors and liver toxicity induced by thioacetamide in rats
}

\author{
Banafsheh Soosani ${ }^{1}$, Hossein Sazegar ${ }^{2 *}$ \\ ${ }^{1}$ Department of Biology, Faculty of Sciences, Shiraz Branch, Islamic Azad University, Shiraz, Iran \\ ${ }^{2}$ Department of Biology, Faculty of Sciences, Shahrekord Branch, Islamic Azad University, Shahrekord, Iran
}

\section{A R T I C L E I N F O}

Article Type:

Original Article

Article History:

Received: 9 August 2017

Accepted: 20 October 2017

\section{Keywords:}

Thioacetamide

Medicinal plants

Thyme daenensis

TNF cytokines

IL-6 cytokine

\begin{abstract}
A B S T R A C T
Introduction: Thioacetamide (TAA) intoxication is underlying acute liver damage, inflammation, and tissue necrosis. The aim of this study was to evaluate of Thymus daenensis extract effect on acute liver disease induced by the thioacetamide and its effects on the tumor necrosis factor- $\alpha$ (TNF- $\alpha$ ), interleukin 6 (IL-6) cytokines.

Methods: In an experimental study, 36 male Wistar rats were divided into 6 groups of 6 each. The amount of $0.03 \mathrm{~g}$ thioacetamide dissolved in $1 \mathrm{~mL}$ of distilled water was injected intraperitoneally to all mice groups except the control group for 3 weeks, twice a week. The negative control group received only thioacetamide and the other groups received $8 \mathrm{mg} / \mathrm{kg}$ silibinin by gavage, other than to thioacetamide. The experimental groups, after injection of thioacetamide were treated with 5,10 or $20 \mathrm{mg} / \mathrm{kg}$ extract of T. daenensis for 2 weeks. Peripheral blood samples were taken from the rats' hearts after general anesthesia. Then, TNF- $\alpha$ and IL- 6 cytokines levels were measured by Elisa kits. Pathology evaluation was also examined on liver.

Results: TNF- $\alpha$ and IL- 6 levels decreased in the groups treated with $5 \mathrm{mg} / \mathrm{mL}$ (respectively, $P=0.001, P=0.05), 10 \mathrm{mg} / \mathrm{mL}(P<0.001, P<0.001$, respectively) and $20 \mathrm{mg} / \mathrm{mL}(P<0.001$, $P<0.001)$ extracts compared to thioacetamide group. Histopathological studies indicated that liver lesions were improved in mice treated with $T$. daenensis extract compared with thioacetamide group.

Conclusion: Thymus daenensis extract has anti-inflammatory and protective effects on liver toxicity induced by thioacetamide. Hence, it might be used for this purpose or for similar toxicities.
\end{abstract}

Implication for health policy/practice/research/medical education:

Thyme daenensis extracts have antioxidant and anti-inflammatory properties and can improve liver injury in mice by decreasing pro-inflammatory TNF and IL-6 cytokines. So, this extract might be used as anti-inflammatory and hepato-protective agent.

Please cite this paper as: Soosani B, Sazegar H. Effects of Thymus daenensis on inflammatory factors and liver toxicity induced by thioacetamide in rats. J Herbmed Pharmacol. 2018;7(1):56-60. doi: 10.15171/jhp.2018.10

\section{Introduction}

In recent decades, low patient satisfaction from the consumption of synthetic drugs, due to high costs and side effects of these medications caused an increased tendency to traditional treatments (1). Herbal usage to treat a massive spectrum of diseases is developing rapidly. In recent studies special attention has been paid to the protective effects of antioxidants by natural origin compounds against poisoning caused by chemical agents (2). Phenolic compounds with antioxidant activities have been shown to possess protective effects on various organs (3).

Thymus daenensis (Thyme) is an aromatic plant from Lamiaceae family that is well known as mediator agent in the synthesis of aromatic chemicals and antibacterial agent against especially oral bacteria. Furthermore, its antibacterial effects against Salmonella and Aspergillus have been reported (4). T. daenensis is the most important type of thyme in Iran (5). Thymol and carvacrol are 2 original phenolic component of thyme oil, which their concentrations are different between $3 \%$ to $6 \%$. In addition, linalool is the main non-phenolic constituent of 
the Thyme (6).

Thioacetamide (TAA) has been used for several years to induce a model of acute liver injury in rats (7). TAA is used as an antifungal agent and is a powerful oxidizing agent. It could be oxidized to active and toxic metabolites called, thioacetamide oxide, by the liver cell microsomes enzyme cytP450B (8). It attacks to membrane proteins and lipids, causing degradation of them, peroxidation of lipids and oxidative stress (7).

The correlation between inflammation and oxidative stress in the course of liver injury is indisputable (9). The systemic inflammatory response is mediated by activated pro-inflammatory cytokines such as tumor necrosis factor- $\alpha$ (TNF- $\alpha$ ), interleukins (IL-1 $\beta$ and IL-6) and oxygen radicals which may sensitize hepatocytes to the toxicity and damage (10). The TNF-a or IL-6 gene knocked out mice had partial ability to regenerate liver and after liver damage had increased mortality rate (11). Thus, aim of this study was to investigate the effects of Thymus daenensis on serum IL- 6 and TNF- $\alpha$ levels as well as hepatotoxicity induced by thioacetamide in rats.

\section{Material and Methods}

\section{Thymus daenensis leaf extraction}

Daenensis aerial parts of thyme plant collected from Chaharmahal and Bakhtiari province mountainous were dried in the room with airflow, away from direct sunlight, in normal temperature and humidity. Then, the plant parts were ground by electric mill to powder. The resulting powder was mixed with ethanol and filtered after 5 hours. The obtained extract was dried using Rotary evaporator. Selected doses of the extract $(5,10$ and $20 \mathrm{mg} / \mathrm{kg})$ were used in this study.

\section{Animals}

Three-month old male Wistar rats, $300 \pm 20 \mathrm{~g}$ in weight were obtained from the animal laboratory facilities of Isfahan University of Medical Science. Islamic Azad University of Shiraz Ethics Committee approved the animal protocols. All experimental animals were housed in standard environmental conditions in cages maintained at an ambient temperature of $25 \pm 2^{\circ} \mathrm{C}$ and received 12 hours of light and dark daily.

\section{Experimental design}

A total of 36 rats were randomly divided into 6 experimental groups, 6 of rats each. The experimental groups were treated as follows:

1. Rats of group 1 were served as controls and intraperitoneally injected with saline solution $(0.9 \%$ $\mathrm{NaCl}$ ), twice weekly for 3 weeks.

2. Rats of group 2 were given $100 \mathrm{mg} / \mathrm{kg}$ body weight of TAA (Sigma-Aldrich Corp., St. Louis, MO, USA) by intraperitoneal injection, twice weekly for 3 weeks.

3. Rats of group 3 were intraperitoneally injected with
TAA at the same dose given to group 2 and were orally supplemented with silibinin in the $8 \mathrm{mg} / \mathrm{kg}$ body weight/day for 3 weeks.

4. Rats of group 4 were intraperitoneally injected with TAA at the same dose given to group 2 and were orally supplemented with $T$. daenensis leaves extract at a dose of $5 \mathrm{mg} / \mathrm{kg}$ body weight/day for 3 weeks.

5. Rats of group 5 were intraperitoneally injected with TAA at the same dose given to group 2 and were orally supplemented with $T$. daenensis leaves extract at a dose of $10 \mathrm{mg} / \mathrm{kg}$ body weight/day for 3 weeks.

6. Rats of group 6 were intraperitoneally injected with TAA at the same dose given to group 2 and were orally supplemented with $T$. daenensis leaves extract at a dose of $20 \mathrm{mg} / \mathrm{kg}$ body weight/day for 3 weeks.

Blood serum analyses

After 48 hours of the last gavage, the experimental animals were fasted for 12 hours, water was not restricted, and then anaesthetized with intraperitoneal injection of ketamine and xylazine. Blood samples were taken from the mice hearts. The collected blood was centrifuged at $4000 \mathrm{rpm}$ for 20 minutes and serum was separated. TNF- $\alpha$ and IL- 6 cytokines (Eastbiopharm company) were measured by ELISA kits.

Histopathological examinations

After blood sampling, the rats were dissected and the liver tissues were preserved in $10 \%$ buffered formalin immediately after removal from the animals, embedded with paraffin. After routine processing, paraffin sections of each tissue were cut into $4 \mathrm{~mm}$ thickness and stained with hematoxylin and eosin. All liver sections were examined using a light microscope and photographed. The data were analyzed using the SPSS version 12.0. Each value was expressed as mean \pm standard deviation (SD) and values were analyzed using two-way analysis of variance (ANOVA) to determine differences between the mean values of the factors in experimental groups. $P$ values less than 0.05 were considered as significant.

\section{Results}

The mean of TNF- $\alpha$ and IL- 6 cytokines in different groups are shown in Table 1 and Figures 1 and 2. TAA administration to normal rats caused significant elevation of serum TNF- $\alpha(23.20 \pm 1.02)$ and IL-6 (84.83 \pm 1.47$)$ cytokines compared with control TNF $(14.23 \pm 1.69)$ $(P<0.001)$ and control IL-6 rats $(73.33 \pm 2.42)(P<0.001)$. The level of TNF- $\alpha$ statistically decreased in rats treated with TAA plus $T$. daenensis leaves extract at a dose of 5 $\mathrm{mg} / \mathrm{kg}(19.20 \pm 1.87)(P=0.001), 10 \mathrm{mg} / \mathrm{kg}(17.00 \pm 1.14)$ $(P<0.001)$.and $20 \mathrm{mg} / \mathrm{kg}(15.41 \pm 1.20)(P<0.001)$ when compared with TAA group (Figure 1). Moreover, reduction in the level of serum IL- 6 was observed in the rats treated with TAA plus $T$. daenensis leaves extract at a dose of 5 
Table 1. Comparison of Mean \pm SD of TNF and IL-6 cytokines in studied groups

\begin{tabular}{lccccc}
\hline & Control & TAA & Silibinin & $\begin{array}{c}\text { TAA+ thyme } \\
\mathbf{5} \mathbf{~ m g} / \mathbf{k g}\end{array}$ & $\begin{array}{c}\text { TAA+ thyme } \\
\mathbf{1 0} \mathbf{m g} / \mathbf{k}\end{array}$ \\
\hline TNF & $14.23 \pm 1.69$ & $23.20 \pm 1.02^{*}$ & $18.15 \pm 1.47^{* *}$ & $19.20 \pm 1.87^{* *}$ & $17.00 \pm 1.14 * *$ \\
IL-6 & $73.33 \pm 2.42$ & $84.83 \pm 1.47^{*}$ & $78.50 \pm 2.58^{* *}$ & $81.33 \pm 1.36$ & $78.16 \pm 1.47^{* *}$ \\
\hline
\end{tabular}

$* P<0.001$ compared with control group.

$* * P \leq 0.001$ Compared with TAA group.

$(81.33 \pm 1.36)(P=0.054), 10(78.16 \pm 1.47)(P<0.001)$ and $20(77.00 \pm 2.36) \mathrm{mg} / \mathrm{kg}(P<0.001)$ compared with TAA group (Figure 2).

The levels of TNF and IL- 6 cytokines in the rats treated with Silibinin +TAA were found respectively $(18.15 \pm 1.47)$ and $(78.50 \pm 2.58)$ which were significantly less than the ones in the rats treated with thioacetamide (for both of them $P<0.001$ ) (Table 1).

Light microscopic examination indicated a normal structure of the liver in the control rats. In the rats treated with TAA, there were marked space dilation of sinusoid, vacuolar and degenerative changes of hepatocytes and an increase in the volume of the nucleus of hepatocytes.

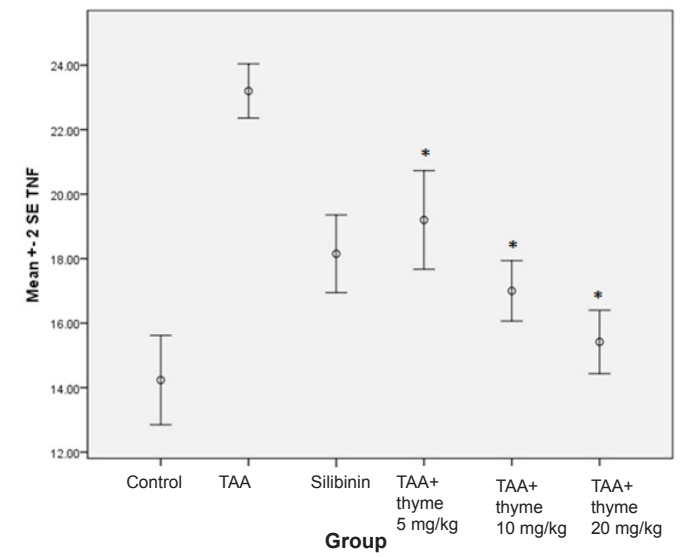

Figure 1. The mean serum level of TNF in the studied groups. ${ }^{*} P \leq 0.001$ Compared with TAA group. .

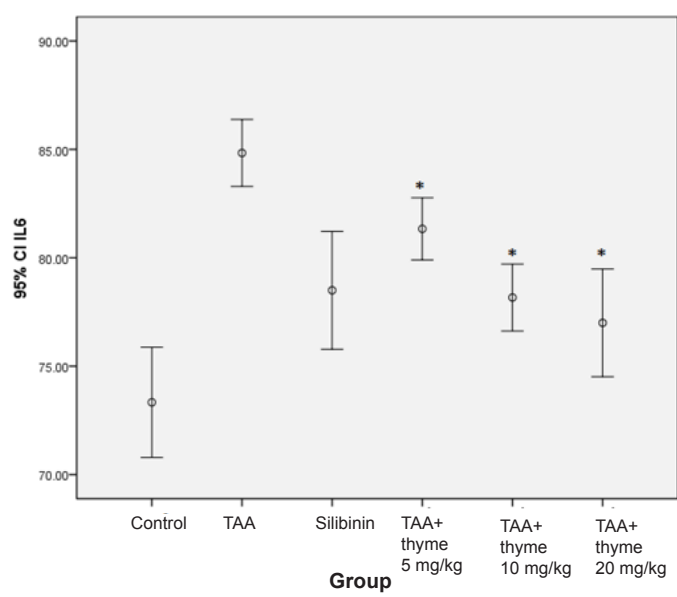

Figure 2. The mean serum level of IL-6 in the studied groups. ${ }^{*} P \leq 0.001$ compared with TAA group.
Nevertheless, in the group treated with Thyme, severe congestion of central venous and presence of mild connective tissue were seen in the rats which received lower concentration of Thyme. By increasing the dosage, it was found evidence of connective tissue in the portal, the vein congestion of portal area, sinusoid mild hyperemia, changes in the structure of liver lobules and disruptive hepatocytes was more acquainted with vesicular nuclei. In the group that received $\mathrm{TAA}+$ Silibinin, necrosis, cytoplasmolisis and degenerative changes around central hepatocytes and central venous dilatation were seen (Figure 3).

\section{Discussion}

The influence of $T$. daenensis preparations on TAAinduced liver injury was determined by assessing histopathologic examinations and serum levels of TNF- $\alpha$ and IL-6. In our study, hepatotoxicity induced by TAA was reflected by a marked elevation of TNF- $\alpha$ and IL- 6 activities, but also by notable histopathologic alterations. This is in agreement with the results of many earlier studies using a model of TAA -induced liver damage $(7,12,13)$. Administration of thioacetamide produces thioacetamide S-oxide by cytochrome P 450 enzyme in liver microsomes (14). S-oxide causes oxidative stress and damages to liver cells and eventually caused necrosis and apoptosis of these cells. The free radicals produced by thioacetamide invade the membranes of liver cells and cause lipid peroxidation. This peroxidation makes membranes less fluidity and changes the permeability which facilitates the release of substances such as cytokines from inside the cells into cytoplasm (7).

Administration of thyme preparations independence dose significantly decrease neither proinflammatory cytokines level nor histological markers of hepatic function, when compared to the TAA-treated group. Aziza et al (15) Nafees et al (16) reported the protective effect of thyme species from different regions on liver injury.

Treatment with different concentrations of thyme essence significantly reduced proinflammatory cytokine levels as well as histological markers of liver function compared with the TAA-treated group. Protective effects of thyme species and its effector components have been reported in the improvement of liver damage $(15,16)$.

Extract of Thyme leaves has been shown to reduce oxidative stress and liver inflammation induced by aflatoxine in Wistar rats (17). Our result indicated treatment with $T$. 

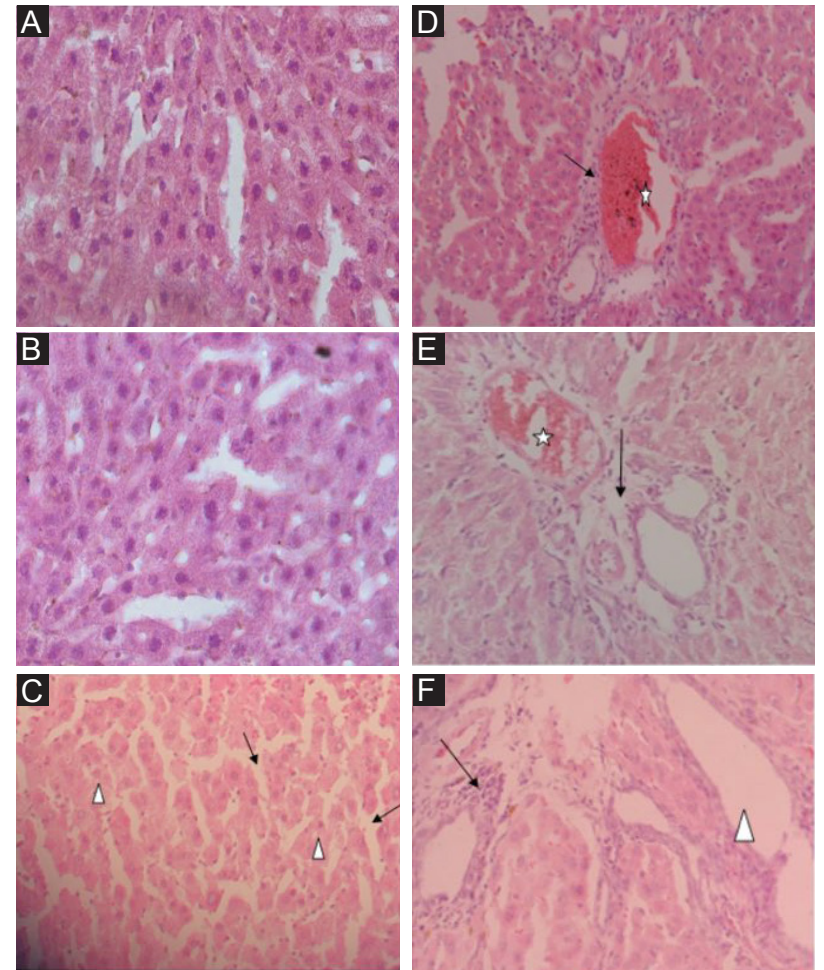

Figure 3. Photomicrographs of liver sections in each group. (A) Control, (B) Silibinin, (C) TAA, (D) TAA + Thyme $5 \mathrm{mg} / \mathrm{kg}$, (E) TAA + Thyme $10 \mathrm{mg} / \mathrm{kg}$, (F) TAA + Thyme $20 \mathrm{mg} / \mathrm{kg}(\times 400)$.

daenensis extract led to significant decrease in TNF- $\alpha$, IL-6 serum levels compared with the control group, and TAA group (positive control). Our findings also revealed that the protective effects of Thyme leave extracts were dose dependent as $20 \mathrm{mg} / \mathrm{kg}$ had the highest liver protective effect. High concentrations of Thyme have been reported to cause cytotoxicity and liver damage through generation of ROS (18). Difference among the results might be due to Thyme species and Thyme formulated types. They used tincture and syrup types of Thyme on carbon tetrachloride-induced acute liver injury in rats.

Moreover, pathological findings confirmed the protective effect of $T$. daenensis extracts on liver tissue. So that the liver injury significantly decreased in $T$. daenensis extracts groups. The effect was dose-dependent since the $20 \mathrm{mg} /$ $\mathrm{dL}$ extract had the most protective effect.

In addition, increased oxidative stress could be due to activated neutrophils, macrophages and monocytes that were reported to release various malicious pro-oxidants that might contribute to cellular damage (19). It should be noted that Thyme daenensis extract includes flavonoids which possess antioxidant activity.

\section{Conclusion}

Thyme daenensis can improve liver injury in mice by decreasing proinflammatory TNF and IL-6 cytokines.

\section{Acknowledgements}

This article was derived from the thesis of Banafsheh
Soosani approved at the Islamic Azad University, Shiraz Branch, Shiraz, Iran. Hereby, we gratefully appreciate the spiritual assistance of the Research Deputy of this university and are also grateful to the participants of this study.

\section{Authors' contributions}

BS was the main researcher and performed the experiments. HS supervised the research, revised and copyedited the manuscript. All read and confirmed the final version of the manuscript for publication.

\section{Conflict of interests}

The authors declared no competing interests.

\section{Ethical considerations}

Ethical issues in research have been completely observed by the authors.

\section{Funding/Support}

This research was financially supported by Islamic Azad University, Shiraz Branch, Iran (grant No. 13330509951001).

\section{References}

1. Al-Attar AM, Shawush NA. Influence of olive and rosemary leaves extracts on chemically induced liver cirrhosis in male rats. Saudi J Biol Sci. 2015;22(2):157-63. doi: 10.1016/j. sjbs.2014.08.005.

2. Abdel-Wahhab KGE, El-Shamy KA, El-Beih NAE, Morcy FA, Mannaa FAE. Protective effect of a natural herb (Rosmarinus officinalis) against hepatotoxicity in male albino rats. Comunicata Scientiae. 2011;2(1):9-17.

3. Amarowicz R, Zegarska Z, Rafalowski R, Pegg RB, Karamac M, Kosinska A. Antioxidant activity and free radicalscavenging capacity of ethanolic extracts of thyme, oregano, and marjoram. Eur J Lipid Sci Technol. 2009;111(11):11117. doi: 10.1002/ejlt.200800170.

4. Ahanjan M, Ghaffari J, Nasolahie M, Mirabi A, Mohammadpour G. Antibacterial potential of essential oil of medicinal plant Satureja bachtiarica Bunge against human pathogenic bacteria. Planta Medica. 2011;77(12):PM1. doi: 10.1055/s-0031-1282759.

5. Kashkooli AB, Saharkhiz MJ. Essential Oil compositions and natural herbicide activity of four Denaei Thyme (Thymus daenensis Celak.) Ecotypes. Journal Essential Oil Bearing Plants. 2014;17(5):859-74. doi: 10.1080/0972060X.2014.884946.

6. Al-Badr NA. Effect of thyme powder, extract and oil on carbon tetrachloride-induced liver injury. J Am Sci. 2011;7(3):221-7.

7. Rezaei A, ShekarForoush S, Changizi Ashtiyani S, Aqababa $\mathrm{H}$, Zarei A, Azizi M, et al. The effects of Artemisia aucheri extract on hepatotoxicity induced by thioacetamide in male rats. Avicenna J Phytomed. 2013;3(4):293-301.

8. Kantah MK, Kobayashi R, Sollano J, Naito Y, Solimene U, Jains S, et al. Hepatoprotective activity of a phytotherapeutic formula on thioacetamide--induced liver fibrosis model. Acta Biomed. 2011;82(1):82-9.

9. Hamzawy MA, El-Denshary ESM, Hassan NS, Manaa F, 
Abdel-Wahhab MA. Antioxidant and hepatoprotective effects of Thymus vulgaris extract in rats during aflatoxicosis. Global J Pharmacol. 2012;6(2):106-17.

10. Li J, Zhu X, Liu F, Cai P, Sanders C, Lee WM, et al. Cytokine and autoantibody patterns in acute liver failure. J Immunotoxicol. 2010;7(3):157-64. doi: $10.3109 / 15476910903501748$.

11. Bohm F, Kohler UA, Speicher T, Werner S. Regulation of liver regeneration by growth factors and cytokines. EMBO Mol Med. 2010;2(8):294-305. doi: 10.1002/emmm.201000085.

12. Avraham Y, Israeli E, Gabbay E, Okun A, Zolotarev O, Silberman I, et al. Endocannabinoids affect neurological and cognitive function in thioacetamide-induced hepatic encephalopathy in mice. Neurobiol Dis. 2006;21(1):237-45. doi: $10.1016 /$ j.nbd.2005.07.008.

13. Okuyama H, Nakamura H, Shimahara Y, Araya S, Kawada $\mathrm{N}$, Yamaoka $\mathrm{Y}$, et al. Overexpression of thioredoxin prevents acute hepatitis caused by thioacetamide or lipopolysaccharide in mice. Hepatology. 2003;37(5):101525. doi: 10.1053/jhep.2003.50203.

14. Kim KH, Bae JH, Cha SW, Han SS, Park KH, Jeong TC. Role of metabolic activation by cytochrome P450 in thioacetamide-induced suppression of antibody response in male BALB/c mice. Toxicol Lett. 2000;114(1-3):225-35.

15. El-Nekeety AA, Mohamed SR, Hathout AS, Hassan NS, Aly
SE, Abdel-Wahhab MA. Antioxidant properties of Thymus vulgaris oil against aflatoxin-induce oxidative stress in male rats. Toxicon. 2011;57(7-8):984-91. doi: 10.1016/j. toxicon.2011.03.021.

16. Nafees S, Ahmad ST, Arjumand W, Rashid S, Ali N, Sultana S. Carvacrol ameliorates thioacetamideinduced hepatotoxicity by abrogation of oxidative stress, inflammation, and apoptosis in liver of Wistar rats. Hum Exp Toxicol. 2013;32(12):1292-304. doi: $10.1177 / 0960327113499047$.

17. Abdel-Aziem SH, Hassan AM, El-Denshary ES, Hamzawy MA, Mannaa FA, Abdel-Wahhab MA. Ameliorative effects of thyme and calendula extracts alone or in combination against aflatoxins-induced oxidative stress and genotoxicity in rat liver. Cytotechnology. 2014;66(3):457-70. doi: 10.1007/s10616-013-9598-7.

18. Raskovic A, Pavlovic N, Kvrgic M, Sudji J, Mitic G, Capo I, et al. Effects of pharmaceutical formulations containing thyme on carbon tetrachloride-induced liver injury in rats. BMC Complement Altern Med. 2015;15:442. doi: 10.1186/ s12906-015-0966-z.

19. Hamed G, Mohammad Bahgat N, Abdel Mottaleb F, Emara M. Effect of flavonoid quercetin supplement on the progress of liver cirrhosis in rats. Life Sci J. 2011;8(2):641-51. 